\title{
First ectomycorrhizal syntheses between Astraeus sirindhorniae and Dipterocarpus alatus (Dipterocarpaceae), pure culture characteristics, and molecular detection
}

\author{
NUTTIKA SUWANNASAI ${ }^{1}$, PREEYAPORN DOKMAI ${ }^{1}$, AKIYOSHI YAMADA ${ }^{2}$, ROY WATLING ${ }^{3}$, \\ CHERDCHAI PHOSRI ${ }^{4, \vee}$ \\ ${ }^{1}$ Department of Microbiology, Faculty of Science, Srinakharinwirot University. Bangkok 10110, Thailand \\ ${ }^{2}$ Department of Bioscience \& Biotechnology, Faculty of Agriculture, Shinshu University. 8304 Minami-minowa, Nagano 399-4598, Japan \\ ${ }^{3}$ Caledonian Mycological Enterprises. Crelah, 26 Blinkbonny Avenue, Edinburgh, EH4 3HU, Scotland \\ ${ }^{4}$ Faculty of Science, Nakhon Phanom University, Nakhon Phanom 48000, Thailand. `email: cherd.phosri@ gmail.com
}

Manuscript received: 6 October 2019. Revision accepted: 24 December 2019

\begin{abstract}
Suwannasai N, Dokmai P, Yamada A, Watling R, Phosri C. 2020. First ectomycorrhizal syntheses between Astraeus sirindhorniae and Dipterocarpus alatus (Dipterocarpaceae), pure culture characteristics, and molecular detection. Biodiversitas 21: 231-238. This study provides the first mycorrhization of Astraeus sirindhorniae and its cultural characteristics on nutrient media. An attempt has been made to introduce spore suspension and mycelial inocula of A. sirindhorniae onto seedlings of Dipterocarpus alatus. After 6 months seedlings were harvested, measured for growth and morphological descriptions of the ectomycorrhizas formed with $D$. alatus seedlings were made. The fungus has increased the growth of $D$. alatus seedlings. Further, it can be confirmed that the primers designed (GAPK126F/GAPK379R) have been successful when applied for the detection of ectomycorrhizal formation of $A$. sirindhorniae in vivo.
\end{abstract}

Keywords: Boletales, Dipterocarpaceae, DNA barcode, Ectomycorrhiza, edible mushroom

\section{INTRODUCTION}

Astraeus is a star-shaped fungus belonging to the family Diplocystidiaceae (Boletales, Basidiomycota) (Binder and Hibbett 2006). A study developed by Phosri et al. (2013) clearly demonstrates that A. hygrometricus as previously circumscribed, to be not a single species but made up of a number of cryptic species. It is widely distributed in warm temperate to subtropical and tropical regions, particularly in sandy soils and forms ectomycorrhizal association with various tree species (Petcharat 2004, Phosri et al. 2004, 2007, 2013, Yomyart 2008, Kaewgrajang et al. 2013). It is one of the uncultured fungi producing commercially valuable mushrooms which are considered delicacies by local people in the north and north-eastern parts of Thailand and neighborhood to Laos. (Phosri et al. 2004). Three species of Astraeus are present in Thailand; A. asiaticus, $A$. odoratus and the recently described, $A$. sirindhorniae (Phosri et al. 2004, 2007, 2014). Fresh basidiomes of $A$. asiaticus and A. odoratus are regularly found on sale in domestic markets during the beginning of the rainy season in Thailand from May-June. Presently the wholesale price of fresh basidiomes ranges from 300-500 Baht (\$8-14 US) per kilogram (Phosri pers.com.). Excess collections are preserved in saline and exported to neighboring countries. So far, A. sirindhorniae has been recorded from only two localities in Thailand, viz. Chiang Mai and Chiyaphum provinces. The two locations in which $A$. sirindhorniae was found are considered as highland dipterocarp forests, about $640 \mathrm{~m}$. (Phosri et al.
2014). As far as field observations are concerned, this Astraeus appears rather restricted in its distribution and although consumed the taste and odor of $A$. sirindhorniae are both similar to A. odoratus (Phosri et al. 2014) but it has not yet become as popular as A. odoratus in terms of a natural food resource.

Dipterocarps are one of the most important families of timber trees in Thailand and Southeast Asia. They are widely distributed in lower Myanmar, Laos, Thailand, Cambodia, South Vietnam, the Andaman Islands, Indonesia, and Malaysia. They produce high-quality wood and provide a source of non-timber forest products such as resins and oils (Boontawee 2001). Because of their important role in ecosystems, a research priority should be given to the Dipterocarpaceae although many reforestation programs for the provision of high-quality timber have focused on fast-growing exotic trees such as eucalypts (Brearley 2011). Over the past 50 years, former King Bhumibol has raised the issue of the loss of dipterocarps esp. Dipterocarpus alatus from Thailand and through a Royal initiative, a re-afforestation program draws attention amongst several sectors for the conservation of endangered dipterocarp populations. Since then reforestation programs in Thailand with dipterocarps species have been attempted and resulted in a total of approximately 2,080 ha (Boontawee 2001). Members of the Dipterocarpaceae form symbiotic root-inhabiting fungal associations with hundreds of ectomycorrhizal (ECM) fungal species (Watling and Lee 1995, 1998, 2007, Lee et al. 2002, 2003 Brearley et al. 2003, 2006, 2007, 2011, 2012). Such reports 
fail to indicate that members of the genus Astraeus are frequent, hypogeous associates. They form putative ectomycorrhizal associations with several host tree species including Shorea siamensis, S. roxburghii, S. farinosa, D. alatus, D. intricatus, D. Obtusifolius and Hopea odorata (Petcharat 2004, Phosri et al. 2004, 2007, 2013, Yomyart 2008, Kaewgrajang et al. 2013, 2019). This strongly suggests that members of this genus are very important ectomycorrhizal components.

The present study was undertaken as A. sirindhorniae had not been maintained in culture nor its ecological parameters demonstrated. An attempt was made therefore to study the effects of the cultural conditions on the biomass production of $A$. sirindhorniae. Further to detail descriptions for the fungal characteristics and its mycorrhizal morphologies. An additional aim was to produce primers designed for A. sirindhorniae as a means of molecular detection in nature after out-planting into the field.

\section{MATERIALS AND METHODS}

\section{Fungal isolation and cultures}

The basidiomes of $A$. sirindhorniae collected from a single population (N 16 $24^{\prime}$ '13.194" and E 101 ${ }^{\circ} 34^{\prime}$ 47.089", elev. $640 \mathrm{~m}$ asl.) in dry deciduous forests, associated with Dipterocarpus tuberculatus Roxb., Shorea obtusa Wall. and Shorea siamensis Miq. Phu Khieo Wildlife Sanctuary, Chiyaphum province, were isolated for pure culture on modified Norkrans's "C" agar medium (MNC) (Yamada and Katsuya 1995). The cultures were incubated at $30^{\circ} \mathrm{C}$ for $4-5$ days. Fungal mycelium was then transferred to new medium and observed for clampconnections under the microscope (Olympus BX40). Mycelial cultures were maintained on MNC slants at $4^{\circ} \mathrm{C}$ and were routinely sub-cultured every 2 months. Some mature basidiomes of $A$. sirindhorniae were kept at $4^{\circ} \mathrm{C}$ for the spore-inoculum experiments.

\section{Molecular identification of fungi}

Pure cultures of fungal isolates were confirmed by the sequencing of internal transcribed spacer (ITS) region. Genomic DNA was extracted from fresh fungal mycelium using Plant Genomic DNA Extraction kit (Farvogen). The ITS region was amplified using primers ITS1F and ITS4B (Gardes and Bruns 1993). The PCR reaction and cycles were followed by Phosri et al. (2014). Amplicons obtained were purified using PCR/Gel Purification kit (Farvogen) and sequenced at the 1st BASE (Malaysia). The DNA sequences were manually checked and compared to GenBank database using BLAST program.

\section{Effects of media, pH and temperature on mycelial growth and biomass}

Three major effects of media, $\mathrm{pH}$, and temperature on mycelial growth of $A$. sirindhorniae were studied with the selected isolate (GACM13-6). Four different culture media were used viz. MNC, modified Melin-Norkrans (MMN), potato dextrose agar (PDA) and Murashige and Skoog
(MS) (Marx 1969, Straatsma et al. 1986). The initial pH was adjusted to 6 for all types of media with 1N HCL or $1 \mathrm{~N} \mathrm{NaOH}$. Mycelium plugs with $6 \mathrm{~mm}$ diameter obtained from 4 weeks old culture were placed in the middle of the agar plate. The cultures were then incubated at $30^{\circ} \mathrm{C}$ in darkness for 4 weeks. The optimum $\mathrm{pH}$ studies were performed in $25 \mathrm{ml} \mathrm{MNC}$ broth by inoculation with a mycelium plug (6 $\mathrm{mm}$ diameter) of A. sirindhorniae. The pH was adjusted from 4-8 (Stoll and Blanchard 1990, Sanmee et al. 2010). Cultures were then incubated at $30^{\circ} \mathrm{C}$ for 4 weeks. The optimum temperature was determined from cultures on MNC agar medium adjusted to $\mathrm{pH} 6$. Fungal cultures were incubated for 4 weeks at different temperatures viz. $25,30,37^{\circ} \mathrm{C}$ and at room temperature in Thailand $\left(30 \pm 2^{\circ} \mathrm{C}\right)$. Mycelial growth in all experiments was evaluated by measuring weight of mycelia (biomass) after drying the mycelium at $60^{\circ} \mathrm{C}$ for 48 hours. The experiments were set in a completely randomized design with five replicate plates/flasks per treatment.

\section{Mycorrhizal synthesis}

Dipterocarpus alatus seeds collected from Yasothon province were rinsed several times with tap water, and soaked in distilled water overnight. For surface sterilization, the seeds were treated with $5 \%$ hydrogen peroxide $\left(\mathrm{H}_{2} \mathrm{O}_{2}\right)$ solution for $15 \mathrm{~min}$ and rinsed three times with sterile water. All seeds were then placed in plastic baskets $(35 \times 45 \mathrm{~cm})$ covered with moist paper until germination. The germinated seeds with 3-4 cm root length were individually transplanted into polyethylene bags (5 $\mathrm{cm} \times 11 \mathrm{~cm}$ ) containing $250 \mathrm{~cm}^{3}$ autoclaved sandy loam soil $\left(2.0 \mathrm{~g} \mathrm{~kg}^{-1}\right.$ of $\mathrm{N}, 1.7 \mathrm{~g} \mathrm{~kg}^{-1}$ of P, $42 \mathrm{mg} \mathrm{kg}^{-1}$ of $\mathrm{K}, 387$

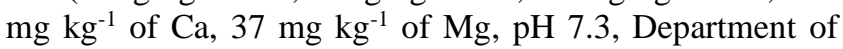
Soil Science, Faculty of Agriculture, Kasetsart University) and peat moss in a 1:1 (v/v) ratio. They were routinely watered with distilled water for a month. Mycelial inocula and spore suspensions of A.sirindhorniae were transferred to 1 month old $D$. alatus seedlings. The mycelium inoculum was prepared in a $250 \mathrm{~cm}^{3}$ glass bottle, containing $200 \mathrm{~cm}^{3}$ vermiculite and peat moss in a $1: 1(\mathrm{v} / \mathrm{v})$ ratio. Thirty milliliters of MNC broth with $\mathrm{pH} 6$ was then added to a bottle prior to autoclaving at $121^{\circ} \mathrm{C}$ for $15 \mathrm{~min}$. Three mycelial plugs of $A$. sirindhorniae (isolate GACM13-6) were introduced into the mixture and incubated at $30^{\circ} \mathrm{C}$ for 4 weeks. This mixture was used as the mycelial inoculum. A spore suspension was prepared from dried mature basidiomes with a drop of Tween 80 in sterile distilled water to ensure homogeneous dispersion. Spore density was measured by using hematocytometry and adjusted to $10^{8} \mathrm{spores} / \mathrm{ml}$. Fifty cubic centimeter of mycelial inocula or $5 \mathrm{~mL}$ of spore-suspension was added to soil of D. alatus seedlings (5 cm deep) near their stems. Ten replications were performed and non-inoculated seedlings were used as controls. All experiments were constructed in a completely randomized design in a greenhouse at the Faculty of Science, Srinakharinwirot University for 6 months. ECM formation was routinely checked every month by sampling lateral roots and observed under the microscope. After 6 months, all seedlings were harvested and the root systems were washed 
with tap water for microscopic examination. Percentage of ECM colonization was examined with a gridline intersection method (Brundrett et al. 1996). Dry weight of roots and shoots of seedlings were measured after being oven-dried at $80^{\circ} \mathrm{C}$ for 48 hours (Kaewgrajang et al. 2013).

\section{Characterization of Astraeus sirindhorniae ectomycorrhiza}

ECM sampled and cleaned root tips were submerged in a Petri dish filled with tap water, then brushed again to removing adhering substrate and soil particles, and observed under a dissecting microscope (Stemi 2000C, Carl Zeiss) for surface color, texture, emanating hyphae, rhizomorphs and ectomycorrhizal branching pattern. Further microscopic observations were conducted under a DIC Nomarski microscope (Olympus BX41) with X40 and X100 objective lenses. Mycorrhizal root tips were handsectioned with razor blades both transversally and longitudinally and mounted with lactic acid on a glass slide for microscopy. Ectomycorrhizal structures in "plain view" (Agerer 1991), i.e., Hartig net, fungal mantle developments, and clamp-connections, were observed.

\section{Specific primer design for ECM detection}

Specific primers were developed for detection of $A$. sirindhorniae ECM root tips from seedlings. This primer pair was designed from the internal transcribed spacers (ITS) sequences of Astraeus species by using Primer-Blast program (www.ncbi.nlm.nih.gor/tools/primer-blast). ECM root tips were extracted for DNA using the CTAB method. PCR condition contained $0.1 \mathrm{mM}$ dNTPs, 0.4 .M of each primer, $1.25 \mathrm{U}$ of TopTaq DNA polymerase and 1x buffer (Qiagen). Thermocycler (BioRad) parameters for amplification were $94^{\circ} \mathrm{C}$ for $5 \mathrm{~min}, 35$ cycles of $94^{\circ} \mathrm{C}$ for 1 $\min , 60^{\circ} \mathrm{C}$ for $30 \mathrm{~s}$, and $72^{\circ} \mathrm{C}$ for $30 \mathrm{~s}$, followed by a $10 \mathrm{~min}$ final extension at $72^{\circ} \mathrm{C}$. PCR products obtained were purified using PCR/Gel Purification kit (Favorgen) and directly sequenced. In addition the primers designed were also checked for cross-reactivity to other Astraeus species; A. odoratus (ASTRAE_16, ASTRAE_18, ASTRAE_27, ASTRAE_66 and ASTRAE_67) and A. asiaticus (ASTRAE_15, ASTRAE_17, ASTRAE_19, ASTRAE_20 and ASTRAE_21) (Phosri et al. 2007) and un-inoculated roots.

\section{Data analysis}

The data obtained from the experiments were subjected to analysis of variance using a statistical program, Minitab 15.0 , and means \pm SD showing statistical significance were compared by Duncan's multiple range test $(\mathrm{p}<0.05)$.

\section{RESULTS AND DISCUSSION}

\section{Cultural characteristic of Astraeus sirindhorniae}

Twelve isolates of $A$. sirindhorniae collected from Chaiyaphum province were obtained on MNC medium. The fungal mycelia were golden brown to dark brown and velvety (Figure 1.D-E). They produced reddish-brown pigments diffused throughout the medium. The hyphae formed numerous clamp-connections (Figure 1.F). These cultural characteristics were similar to A. odoratus (Fangfuk 2010). The diameter of A. sirindhorniae hyphae was 2.5-3.0 $\mu \mathrm{m}$ and rhizomorphs were also observed on medium agar after incubation for 4 weeks. The fastestgrowing isolate, isolate GACM13-6, was selected for further studies for the effects of growth and to produce mycelial inocula. The fungal culture was also extracted for DNA and sequenced on ITS regions. The BLAST result revealed 99\% similarity to A. sirindhorniae (HE681774). The sequence was then deposited in GenBank database as an accession number KT804707.

\section{Effects of media, pH, and temperature on fungal growth and biomass}

The effect of culture media on mycelia growth of $A$. sirindhorniae (isolate GACM13-6) is shown in Figure 2.A. Statistically differences were found among the culture media. The highest biomass yield of mycelial dry weight was significantly observed on $\mathrm{MNC}(85.8 \pm 3.2 \mathrm{mg})$, followed by MS (78.6 $\pm 2.6 \mathrm{mg}$ ) agar media (Figure 2.A). The lowest biomass yield was observed on PDA agar medium $(35.6 \pm 2.9 \mathrm{mg})$. MNC medium has been modified and used in many ECM cultural experiments (Yamada and Katsuya 1995). Astraeus hygrometricus and Boletus edulis have been cultured on MNC medium before testing for ECM synthesis to Pinus densiflora seedlings (Fangfuk et al. 2010; Endo et al. 2014). Whilst MS medium was mostly used for plant tissue cultures, it has been shown to promote some mutualistic association in some fungi such as Phlebopus portentosus (Sanmee et al. 2010; Kumla et al. 2011). Both of these media contain high nutritional content and vitamins. Although PDA medium showed the lowest growth of $A$. sirindhorniae in this study, therefore, the most suitable media for ECM growth appears to depend on not only the fungal species tested but the strain within that species. The $\mathrm{pH}$ of medium is a very important factor for mycelial growth. It was found that the suitable $\mathrm{pH}$ range for mycelial growth of $A$. sirindhorniae in vitro was 5 to 6 and yielded the best result for mycelial growth of $A$. sirindhorniae at $\mathrm{pH} 6(45.7 \pm 2.2 \mathrm{mg})$, followed by $\mathrm{pH} 5.0$ $(31.2 \pm 2.4 \mathrm{mg})$ and $7.0(27.9 \pm 2.0 \mathrm{mg})$ (Figure 2.B). The mycelial growth of $A$. sirindhorniae was less at $\mathrm{pH} 4$ and $\mathrm{pH}$ 8. This result agrees with several studies demonstrating that most ECM fungi prefer a slightly acidic condition in which to grow. The optimum $\mathrm{pH}$ for ECM fungal growth ranges from 5-6 (Hung and Trappe 1983, Yamanaka 2003). However, the potential of ECM fungi to grow at different $\mathrm{pH}$ values also varies between fungal species and isolates. The best $\mathrm{pH}$ value for the mycelial growth of Scleroderma sinnamariense had its optimal growth at $\mathrm{pH} 5$ (Siri-in et al. 2013) whereas Phlebopus portentous had the best growth at pH 4 (Thongklang et al. 2010). In general, fungi grow well in acidic conditions (Wheeler et al. 1991, Rousk et al. 2010) but some species prefer neutral to slightly alkaline conditions. In the rhizosphere where the ECM fungi occur, soil $\mathrm{pH}$ is varied and can strongly influence both ECM fungal growth and formation of mycorrhizas. The $\mathrm{pH}$ from soil in which fruiting bodies of $A$. sirindhorniae grew is neutral (7.03). In this study, although the $\mathrm{pH}$ conditions for 
vegetative growth in vitro are not correlated with the soil $\mathrm{pH}$, these may be required for the species to survive in the form of vegetative hyphae. They can develop mycelia during the early phase but do not form their fruiting bodies at this stage. In neutral conditions, they may infect root tips and form fruiting bodies suggesting that the $\mathrm{pH}$ of the forest soil could be determining factor for the developmental pattern of the fungi (Yamanaka 2003) and also the greatest driver of soil fungi composition than other environmental factors that vary between biomes (Tedersoo et al. 2014). The best temperature for A. sirindhorniae mycelial growth was at $28-30^{\circ} \mathrm{C}$, which exhibited the highest yield of biomass $(80 \pm 2.6 \mathrm{mg})$. The analysis of variance revealed that there were significant differences among temperatures (Figure 2.C). The fungal mycelium did not develop at $37^{\circ} \mathrm{C}$ after incubating for 4 weeks (Figure 2.C). The optimum temperature for the mycelial growth of ECM fungi depended on species and strain. The optimum temperature for mycelial growth of Phlebopus portentosus was at $30^{\circ} \mathrm{C}$. However, in several studies, the maximum biomass yield of several ECM mushrooms was at $25^{\circ} \mathrm{C}$ (Kibar and Peksen 2011). It would appear that the growth of most fungal mycelia decreased considerably at lower temperatures than $20^{\circ} \mathrm{C}$ possible a result of reducing the fungal metabolic activities.

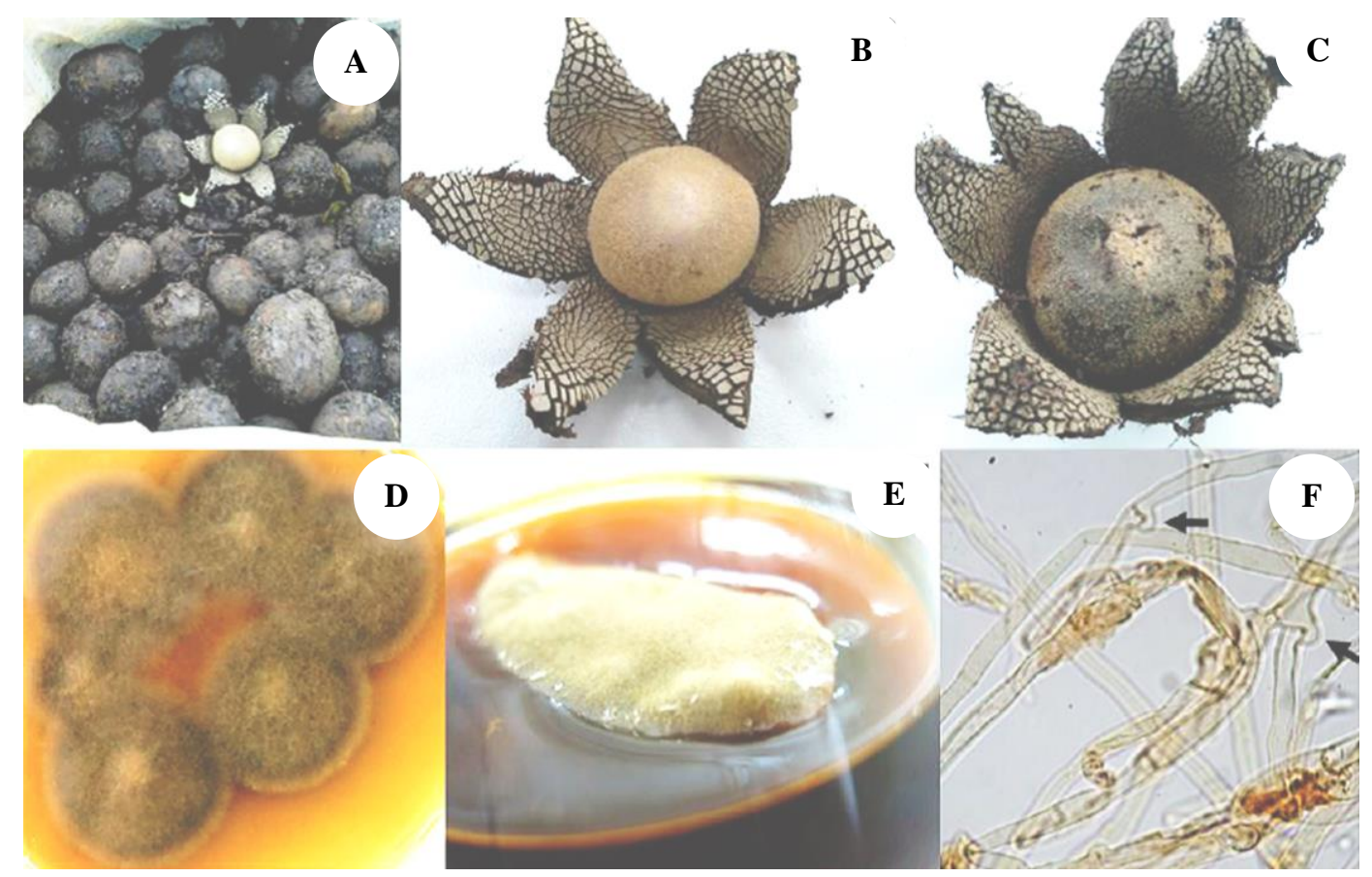

Figure 1 Astraeus sirindhorniae basidiomes and its cultured mycelia A: young basidiomes, B: a matured basidiome with brownish endoperidium, C: a matured basidiome with gray endoperidium, D: isolate GACM13-6 culture on MNC agar medium for 4 weeks, E: isolate GACM13-6 culture on MNC liquid medium for 4 weeks, F: vegetative hyphae and clamp-connection (arrowed)

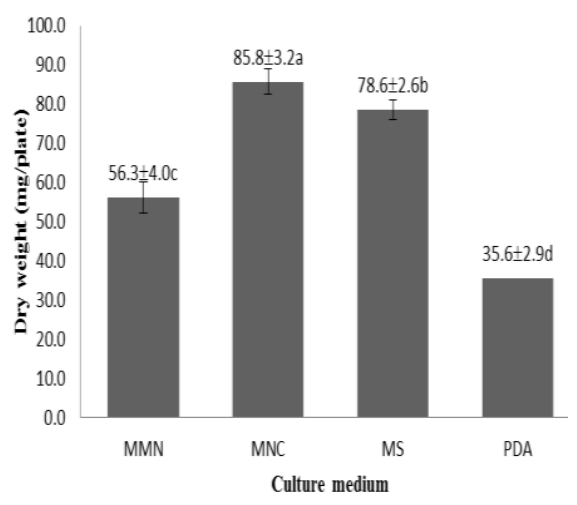

A

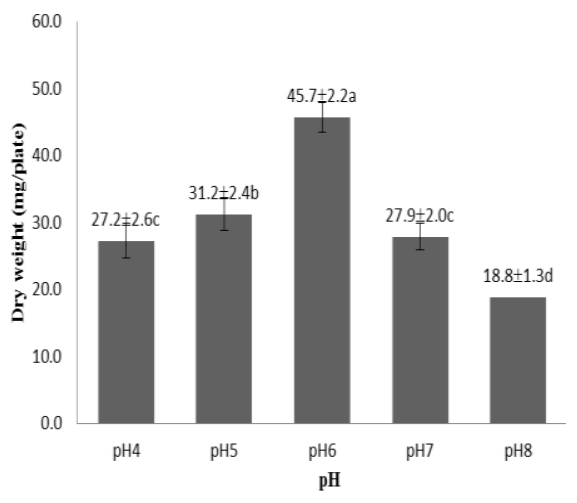

B

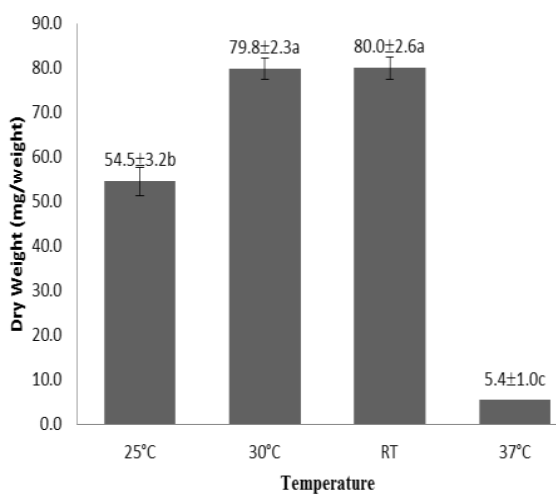

C

Figure 2 Effects of medium (A), pH (B) and temperature $\left({ }^{\circ} \mathrm{C}\right)(\mathrm{C})$ on mycelial growth of Astraeus sirindhorniae; MMN = modified Melin-Norkrans medium, $\mathrm{MNC}=$ modified Norkrans's "C" agar medium, PDA = potato dextrose agar, MS = Murashige and Skoog medium, RT = room temperature. Cultures were incubated for 4 weeks. Means followed by different letters in the columns are statistically different by Duncan's multiple range test $(p<0.05)$. 
Table 1. Seedling height, shoot dry weight and root dry weight (Mean \pm SD) of dipterocarp seedlings at 6 months after inoculated with different Astraeus sirindhorniae inocula.

\begin{tabular}{llccl}
\hline \multicolumn{1}{c}{ Inoculum } & Height $(\mathbf{c m})$ & Shoot dry weight $(\mathbf{g})$ & Root dry weight $(\mathbf{g})$ & Colonization rate $(\%)$ \\
\hline Spore suspension & $36.84 \pm 2.23 \mathrm{a}^{*}$ & $3.89 \pm 0.57 \mathrm{a}$ & $2.78 \pm 0.49 \mathrm{a}$ & $70.6 \pm 5.4 \%$ \\
Mycelium inoculum & $28.95 \pm 2.03 \mathrm{~b}$ & $2.34 \pm 0.28 \mathrm{~b}$ & $1.70 \pm 0.24 \mathrm{~b}$ & $35.6 \pm 10.3 \%$ \\
Control & $25.01 \pm 1.29 \mathrm{c}$ & $1.97 \pm 0.15 \mathrm{c}$ & $1.28 \pm 0.29 \mathrm{c}$ & ND \\
\hline
\end{tabular}

* Number within column not sharing a common letter differ significantly $(\mathrm{p}<0.05)$ by Duncan's multiple pair-wise comparisons. ND = non detect

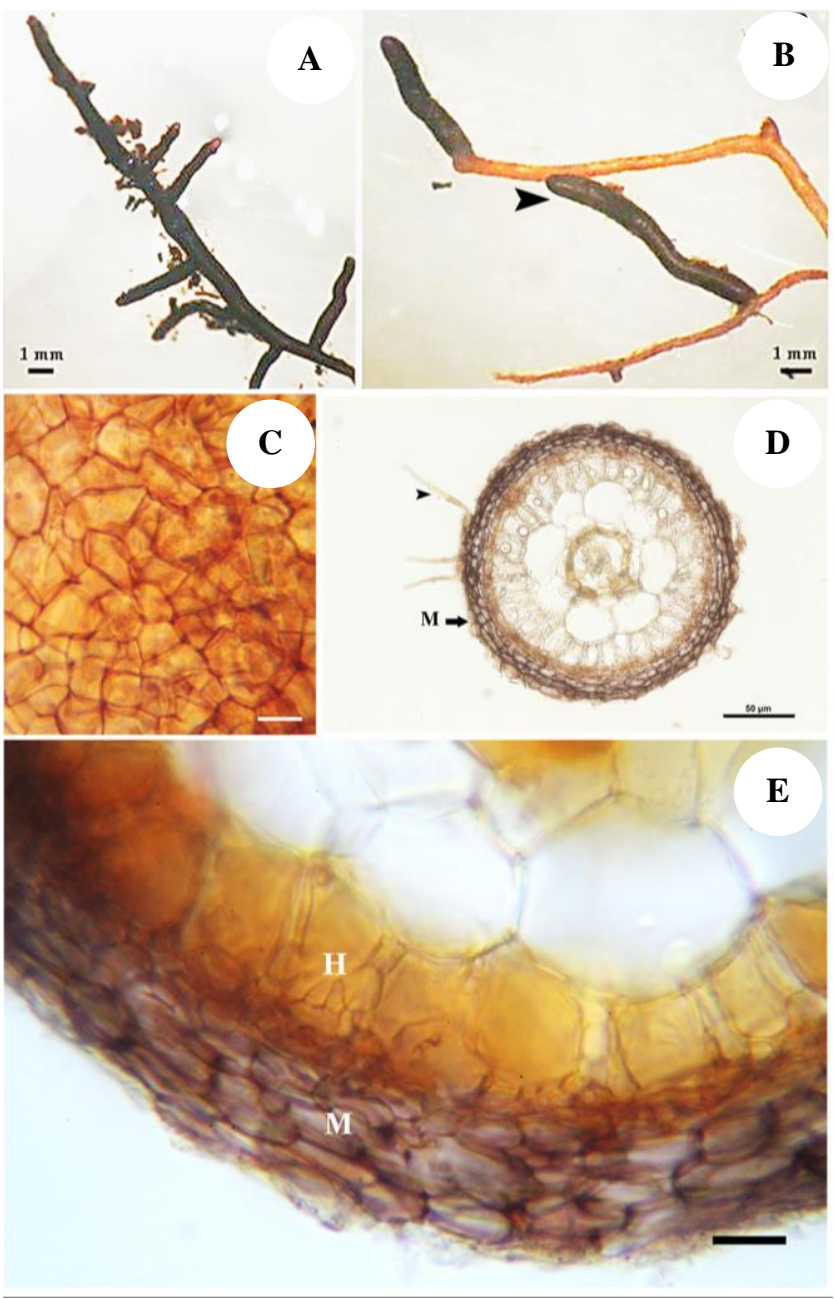

Figure 3 Morphological characteristics of Astraeus sirindhorniae ectomycorrhizal on Dipterocarpus alatus seedling 6 months after inoculated with spore suspension. A-B: pinate (A) or monopodial (B) branching mycorrhizal root tips, C: plectenchymatous hyphal tissue of surface mantle layer $($ bar $=10 \mu \mathrm{m}), \mathrm{D}$ : a transverse section of the mycorrhizal root tip demonstrated external hyphae having clamp-connections (arrowhead) and mantle (arrowed) bar $=50 \mu \mathrm{m}$, E: magnify of mantle $(\mathrm{M})$ and Hartig net $(\mathrm{H})$ structure at the root cortex, bar $=10 \mu \mathrm{m}$

\section{Mycorrhizal synthesis}

Astraeus sirindhorniae isolate GACM13-6 grown for 4 weeks on vermiculite: peat moss in ratio $1: 1(\mathrm{v} / \mathrm{v})$ and containing $30 \mathrm{ml}$ of MNC broth ( $\mathrm{pH} \mathrm{6)}$ was used as mycelial inocula compared to spore-suspension inocula. After six months, D. alatus seedlings were sampled for ECM development. All seedlings were harvested and measured for growth. The ECM formation was observed from both inoculations and no ECM roots were found in the control seedlings. ECM roots were brown to dark brown in color, smooth, and of monopodial-pinnate branching (Figure 3.A-B). External mycelia and rhizomorphs were demonstrable around ECM roots. An obvious mantle had formed composed of a layer of plectenchymatous tissue (Fig 3.C). The thickness of the mantle was 7-10 $\mu \mathrm{m}$ for mycelial inocula and 11-15 $\mu \mathrm{m}$ for spore-suspension inocula. The outer mantle region of ectomycorrhizas showed intertwining hyphae with numerous clamp-connections (Figure 3.C-D). A Hartig net was present in the epidermal layer with a thickness of 23.5$29.7 \mu \mathrm{m} \mu \mathrm{m}$ (Figure 3.E). There are very few published descriptions of dipterocarp-associated Astraeus ECM. Yomyart (2008), Kaewkrajang et al. (2013, 2019) demonstrated that ECM roots of D. alatus, D. tuberculatus, and Shorea roxburghii inoculated with A. odoratus being monopodial-pinnate to irregular pinnate branching with shades of brown color, well-developed mantle and emanating hyphae. Our study provided anecdotal evidence suggesting that $A$. sirindhorniae form similar ECM characteristics. Smits (1983, 1985) suggested that dipterocarp-associated ECM is highly hosted specific. But current study suggests that host specificity of dipterocarp ECM is not as highly specific as claimed by Smits (1983, 1985). Seedlings inoculated with a spore suspension yielded greater colonization $(70.6 \pm 5.4 \%)$ than the mycelial inocula $(35.6 \pm 10.3 \%)$. This finding is similar to recent study by Kaewkrajang et al. (2019) indicate that $30-60 \%$ of the roots formed by the inoculated seedlings of $D$. tuberculatus and $S$. roxburghii inoculated with A. odoratus using spore suspension were ectomycorrhizal roots. Pure mycelial inocula may not remain viable if they are poorly adapted to the biotic or abiotic environments of the greenhouse or forest soils (Chang et al. 1994, 1995). Therefore this could be a cause of a reduction in ECM colonization in our experiment.

\section{Growth of dipterocarp seedlings}

Seedling growth (i.e. height and shoot and root dry weight) was greatest when given spore suspensions, followed by mycelium inoculum and by the controls. A significant difference between both inoculation treatments and the control was detected (Table 1). 

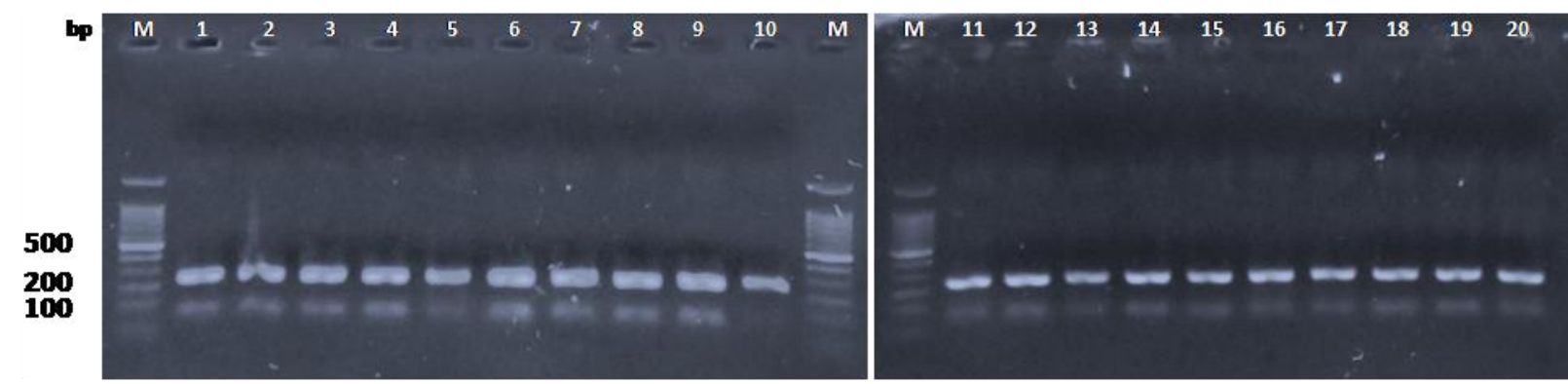

Figure 4. Gel electrophoresis of selected $A$. sirindhorniae ectomycorrhizal roots amplified using GAPK126F/GAPK379R primers. M = 100 bp DNA ladder marker. Lane 1-20 exhibited target DNA bands size approximately $250 \mathrm{bp}$

The effect of $A$. asiaticus and A. odoratus on growth promotion of dipterocarp species were studied (Kaewkrajang et al. 2013, 2019). It is clearly demonstrated that both Astraeus species can stimulate the growth of dipterocarp seedlings after colonization of their root systems (Yomyart 2008, Kaewkrajang et al. 2013, 2019). From our study, the same technique can be applicable and it is apparent that a parallel phenomenon can be found using A. sirindhorniae.

\section{Molecular identification of ectomycorrhizal tips}

One hundred and sixty ECM root tips sampled from both mycelial- and spore- inoculated seedlings were extracted for DNA and amplified by using primers, i.e. GAPK126F (5'-TCAAGACTGTCCCCTCCAGA-3') and GAPK379R (5'-CTAGGA CCTACAACGGG TGC-3'). They were designed for $A$. sirindhorniae detection. The amplicon size was approximately 253 bps. After amplification, all 143 ECM root tips sampled (89.4\% success) gave positive bands at the correct size (Figure 4). Twenty samples were randomly sequenced and then analyzed. All sequences exhibited $100 \%$ similarity to $A$. sirindhorniae (HE681791) from GenBank database. These confirmed that the ECM roots of $D$. alatus were colonized by the inoculated $A$. sirindhorniae and indicates that $D$. alatus can be an ECM host of this fungus. Sequences were deposited in GenBank database as accession numbers KT804708 to KT804737. In addition, the primers were tested for their specificity to closely related species i.e. A. odoratus and A. asiaticus. The results revealed no crossreactivity between those species (data not shown). Therefore, the primers GAPK126F/ GAPK379R may be used for detection of $A$. sirindhorniae ECM formation in situ for large-scale production of mycorrhizal seedlings in further.

As far as field observations are concerned, this Astraeus appears rather restricted in its distribution and although consumed it has not yet become as popular as A. odoratus and $A$. asiaticus in terms of a natural food resource. However, the taste and odor of $A$. sirindhorniae are both similar to A. odoratus (Phosri et al. 2014). It is possible that $A$. sirindhorniae equally possesses a wide dipterocarp host range, although so far it has only been found at higher altitudes. Also, there was limited experimental data available regarding its mycorrhizal synthesis. This earthstar would, therefore, be another good candidate for developing as a food-source and attempting to made and use artificial inoculants for potential re-afforestation trials under the dipterocarp reforestation program esp. with D. alatus. It is hoped that with this approach, seedlings inoculated with $A$. sirindhorniae could improve the early growth of $D$. alatus seedlings grown in tropical forests. Ectomycorrhizal synthesis of A. sirindhorniae, therefore, was established. The A. sirindhorniae was isolated from basidiomes and characterized based on cultures. This study provides the first cultural characteristics of $A$. sirindhorniae on different culture media. It was necessary to characterize pure cultures from material collected in the field and estimate the most suitable conditions for both mycelial growth and inoculum production. Pure cultures of $A$. sirindhorniae were obtained and ectomycorrhization using $D$. alatus seedlings was conducted in addition to using spore suspensions. The synthesized mycorrhizae were successfully established under greenhouse conditions after 6 months and mycorrhizal root tips were developed. For practical use, employing spore suspension of $A$. sirindhorniae would be most likely since the ease of preparation and the positive effect on dipterocarp seedlings growth demonstrated in the present study. However, it is apparent that there are significant challenges in conducting field experimentation for ectomycorrhizal establishment (Tata et al. 2010). The main one is that it is very difficult to create truly non-mycorrhizal controls, especially where natural ECM inocula are already present in the soil. Based on sequences of ITS rDNA, several ECM fungal taxa exist in the topsoil collected from beneath the tree stands of $D$. alatus both in natural forest and plantation (Kaewgrajang et al. 2014). With our designed primer, GAPK126F/GAPK379R, it will be an effective tool for detection of ectomycorrhizal formation of A. sirindhorniae in nature.

In conclusion, our results suggest that $A$. sirindhorniae can be used for mushroom cultivation studies with other dipterocarps such as D. tuberculatus, Shorea obtusa and $S$. siamensis. Possibly other native tree hosts should be incorporated into the re-afforestation program. These observations might help in commercial exploitation and 
return economic benefits to local interests in Thailand and elsewhere. The domestication therefore of A. sirindhorniae is considered worthy of exploration for possible future exploitation.

\section{ACKNOWLEDGMENTS}

We thank the Office of the Higher Education Commission, National Research Council of Thailand and the Matsumae International Foundation for the financial support for this study. We are appreciated to the Head of Phu Khieo Wildlife Sanctuary and staff for sample collection. We are also grateful to the Department of National park, wildlife and plant conservation for supplying the necessary permit to collect specimens (Doc. No. 0907.1/17723) on which the present study is based and without which it could not have been completed.

\section{REFERENCES}

Agerer R. 1987-2002. Colour atlas of ectomycorrhizae. Einhorn, Schwäbisch Gmund, Germany.

Boontawee B. 2001. The status of in situ and ex situ conservation of Dipterocarpus alatus Roxb. in Thailand. In: Thielges BA, Sastrapradja SD, Rimbawanto A (eds) Proceedings of the international conference on ex-situ and in situ conservation of commercial tropical trees, Yogyakarta, Indonesia, 11-13 June 2001.

Binder M, Hibbett DS. 2006. Molecular systematics and biological diversification of Boletales. Mycologia 98: 971-981. DOI: 10.3852/ mycologia.98.6.971.

Brearley FQ. 2006. Differences in the growth and ectomycorrhizal community of Dryobalanops lanceolata (Dipterocarpaceae) seedlings grown in ultramafic and non-ultramafic soils. Soil Biology and Biochemistry 38: 3407-3410. DOI: 10.1016/j.soilbio.2006.05.012.

Brearley FQ. 2011. The importance of ectomycorrhizas for the growth of dipterocarps and the efficacy of ectomycorrhizal inoculation schemes. In: Rai M, Varma A (eds) Diversity and biotechnology of ectomycorrhizae. Springer-Verlag, Berlin, Germany.

Brearley FQ. 2012. Ectomycorrhizal associations of the Dipterocarpeace. Biotropica 44 (5): 637-648. DOI: 10.1111/j.1744-7429.2012. 00862.x

Brearley FQ, Press MC, Scholes JD. 2003. Nutrients obtained from lea litter can improve the growth of dipterocarp seedlings. New Phytologist 160: 101-110. DOI: 10.1046/j.1469-8137.2003.00851.x.

Brearley FQ, Scholes JD, Press MC, Palfner G. 2007. How does light and phosphorus fertilization affect the growth and ectomycorrhizal community of two contrasting dipterocarp species? Plant Ecology 192: 237-249. DOI: 10.1007/s11258-007-9325-6

Brundrett M, Bougher N, Dell B, Grove G, Malajczuk N. 1996. Working with mycorrhizas in forestry and agriculture. ACIAR Monograph 32, ACIAR, Canberra.

Chang YS, Lapeyrie FF, Lee SS. 1994. The survival and competitiveness of Pisolithus tinctorius on outplanted seedlings of Shorea glauca in Malaysia. In: Khoo KC, Appanah S (eds) Proceedings of the fifth round table conference on dipterocarps Chiang Mai, Thailand, 7-10 November 1994. Forest Research Institute of Malaysia, Kepong, Malaysia.

Chang YS, Lee SS, Lapeyrie FF, Yazid SM. 1995. The competitiveness of two strains of Pisolithus tinctorius on seedlings of three species of dipterocarps under nursery and field conditions: preliminary results. In: Wickneswari R, Yahya AZ, Shariff AHM, Haji AD, Khoo KC, Suzuki S, Ishii K (eds) Proceedings of the international workshops of BIO-REFOR, Kangar, Malaysia, 28 November-1 December 1994. BIO-REFOR, IUFRO-SPDC, Tokyo, Japan \& FRIM, Kepong, Malaysia.

Endo N, Kawamura F, Kitahara R, Sakuma D, Fukuda M, Yamada A. 2014. Synthesis of Japanese Boletus edulis ectomycorrhizae with Japanese red pine. Mycoscience 55: 405-416. DOI: 10.1016/j.myc.2013.11.008.
Fangfuk W, Okada K, Petchang R, To-anun C, Fukuda M, Yamada A. 2010. In vitro mycorrhization of edible Astraeus mushrooms and their morphological characterization. Mycoscience 51: 234-241. DOI: 10.1007/s10267-009-0031-1.

Gardes M, Bruns TD.1993. ITS primers with enhanced specificity of basidiomycetes: application to the identification of mycorrhizae and rusts. Mol Ecol 2: 113-118. DOI: 10.1111/j.1365294X.1993.tb00005.x.

Hung LL, Trappe JM. 1983. Growth variation between and within species of ectomycorrhizal fungi in response to $\mathrm{pH}$ in vitro. Mycologia 75: 234-241. DOI: 10.2307/3792807.

Kaewgrajang T, Sangwanit U, Iwasa K, Kodama M, Yamato M. 2013. Effects of ectomycorrhizal fungus Astraeus odoratus on Dipterocarpus alatus seedlings. J Tropical Forest Science 25 (2): 200205.

Kaewgrajang T, Sangwanit U, Kodama M, Yamato M. 2014. Ectomycorrhizal fungal communities of Dipterocarpus alatus seedlings introduced by soil inocula from natural forest and plantation. J For Res 19 (2):260-267. DOI: 10.1007/s10310-0130408-z.

Kaewgrajang T, Sakolrak B, Sangwanit U. 2019. Growth response of Dipterocarpus tuberculatus and Shorea roxburghii seedlings to Astraeus odoratus. Environ Nat Res J 17 (3): 80-88.

Kibar B, Peksen A. 2011. Nutritional and environmental requirements for vegetative growth of edible ectomycorrhizal mushroom Tricholoma terreum. Žemdirbystė Agriculture 98 (4): 409-414.

Kumla J, Danell E, Bussaban B, Lumyong S. 2011. Suitable growth conditions and nutrition factors on in vitro culture of Phlebopus portentosus (Boletales). Chiang Mai J Science 38: 156-159.

Lee SS, Watling R, Noraini SY. 2002. Ectomycorrhizal basidiomata fruiting in lowland rain forests of peninsular Malaysia. Bois et forêts des tropiques 274: 33-43.

Lee SS, Patahayah M. 2003. Host specificity of dipterocarp ectomycorrhizal fungi. In: Aminah H, Ani H, Sim C, Krishnapillay B (eds.). Proceedings of the seventh round-table conference on dipterocarps Kuala Lumpur, Malaysia, 7-10 October 2002. Asia Pacific Association of Forestry Research Institutions, Kuala Lumpur, Malaysia.

Marx DH. 1969. The influence of ectotrophic mycorrhizal fungi on the resistance of pine roots to pathogenic infections. I. Antagonism of mycorrhizal fungi to root pathogenic fungi and soil bacteria. Phytopathology 59: 153-163.

Petcharat V. 2004. Edible Astraeus (Basidiomycota) from Thailand. Nordic J Bot 23: 499-503. DOI: 10.1111/j.17561051.2003.tb00423.x.

Phosri C, Martín MP, Watling R. 2013. Astraeus: hidden dimension. IMA Fungus 4 (2): 347-356. DOI: 10.5598/imafungus.2013.04.02.13.

Phosri C, Martín MP, Sihanonth P, Whalley AJS, Watling R. 2007. Molecular study of the genus Astraeus. Mycological Research 3: 275286. DOI: 10.1016/ j.mycres.2007.01.004.

Phosri C, Watling R, Martín MP, Whalley AJS. 2004. The genus Astraeus in Thailand. Mycotaxon 89: 453-463.

Phosri C, Watling R, Suwannasai N, Wilson A, Martín MP. 2014. A new representative of star-shaped fungi: Astraeus sirindhorniae sp. nov. from Thailand. PloS One 9 (5): e71160. DOI: 10.1371/journal.pone.0071160.

Rousk J, Brookes PC, Bååth E. 2010. Investigating the mechanisms for the opposing $\mathrm{pH}$ relationships of fungal and bacterial growth in soil. Soil Biol Biochem 42: 926-934. DOI: 10.1016/j.soilbio.2010.02.009.

Sanmee R, Lumyong P, Dell B, Lumyong S. 2010. In vitro cultivation and fruit body formation of the black bolete, Phlebopus portentosus, a popular edible ectomycorrhizal fungus in Thailand. Mycoscience 51: 15-22. DOI: 10.1007/s10267-009-0010-6.

Siri-in J, Kumla J, Suwannarach N, Lumyong S. 2014. Culture conditions and some properties of pure culture of ectomycorrhizal fungus, Scleroderma sinnamariense. Chiang Mai J Science 41 (2): 275-285.

Smits, WTM. 1983. Dipterocarps and mycorrhiza - an ecological adaptation and a factor in forest regeneration. Flora Malesiana Bull. 36: 3926-3937.

Smits, WTM. 1985. Specificity of dipterocarp mycorrhiza. In: Molina R (ed). Proceedings of the 6th North American Conference on Mycorrhizae, p. 364. Forest 874 Research Laboratory, Corvallis, Oregon, USA.

Straatsma G, van Griensven LJLD, Bruinsma J. 1986. Root influence on in vitro growth of hyphae of the mycorrhizal mushroom Cantharellus 
cibarius replaced by carbon dioxide. Physiologia Plantarum 67: 521 528. DOI: $10.1111 /$ j. 1399-3054.1986.tb05050.x.

Stoll VS, Blanchard JS. 1990. Buffers: principles and practice. In Deutscher MP (ed) Methods in enzymology vol. 182, Guide to protein purification. Academic Press, San Diego, CA

Tata MH, Van Noordwijk M, Summerbell R, Wegger MJA. 2010. Limited response to nursery-stage mycorrhiza inoculation of Shorea seedlings planted in rubber agroforest in Jambai, Indonesia. New For 39: 51-74. DOI: $10.1007 / \mathrm{s} 11056-009-9155-6$.

Tedersoo L, Bahram M, Põlme S, et al. 2014. Global diversity and geography of soil fungi. Science 346: 6213. DOI 10.1126/science.1256688.

Thongklang N, Hyde KD, Bussaban B, Lumyong S. 2010. Culture condition, inoculum production and host response of a wild mushroom, Phlebopus portentosus strain CMUHH121-005. Maejo International J Sci Technol 5 (3): 413-425.

Watling R, Lee SS. 1995. Ectomycorrhizal fungi associated with members of the Dipterocarpaceae in Peninsular Malaysia-I. J Trop For Sci 7: 657-669.
Watling R, Lee SS. 1998. Ectomycorrhizal fungi associated with members of the Dipterocarpaceae in Peninsular Malaysia-II. J Trop For Sci 10: 421-430.

Watling R, Lee SS. 2007. Mycorrhizal mycodiversity in Malaysia. In: Jones EBG, Hyde KD, Vikineswary S. (eds.) Malaysian fungal diversity. Mushroom Research Centre, University of Malaya \& Ministry of Natural Resources and Environment, Kuala Lumpur, Malaysia.

Wheeler KA, Hurdman BF, Pit JI. 1991. Influence of $\mathrm{pH}$ on the growth of some toxigenic species of Aspergillus, Penicillium and Fusarium. International J Food Microbiol 12: 141-150. DOI: 10.1016/0168-1605 (91)90063-U.

Yamada A, Katsuya K. 1995. Mycorrhizal association of isolates from sporocarps and ectomycorrhizas with Pinus densiflora seedlings. Mycoscience 36: 315-323.

Yamanaka T. 2003. The effect of $\mathrm{pH}$ on the growth of saprotrophic and ectomycorrhizal ammonia fungi in vitro. Mycologia 95 (4): 584-589.

Yomyart S. 2008. Community Structure of Ectomycorrhizal Fungi and Reforestation Application in Dipterocarpaceae. [Dissertation]. Chulalongkorn University, Bangkok. 